\title{
Regionalização da saúde e cooperação federativa no Brasil: o papel dos consórcios intermunicipais
}

\author{
Health regionalization and federative cooperation in Brazil: \\ the role of inter-municipal consortium
}

Lizandro Lui (https://orcid.org/0000-0002-9276-247X) ${ }^{1}$

Letícia Maria Schabbach (https://orcid.org/0000-0002-1828-6030) ${ }^{1}$

Carlise Rigon Dalla Nora (https://orcid.org/0000-0001-5501-2146) ${ }^{2}$

${ }^{1}$ Programa de PósGraduação em Sociologia, Universidade Federal do Rio Grande do Sul (UFRGS). Av. Bento Gonçalves 9500, Bairro Agronomia. 91501970 Porto Alegre RS Brasil. lizandrolui@gmail.com ${ }^{2}$ Escola de Enfermagem, UFRGS. Porto Alegre RS Brasil.

\begin{abstract}
This paper aims to investigate public inter-municipal health consortium operation in Brazil. To this end, a qualitative documentary analysis was conducted on the content of the agreements between the consortia and the Federal Government, available at the Transparency Portal of the Federal Government, from 1996 to 2016. The results cover two categories: agreements concluded in Brazil and the content of the agreements signed by an inter-municipal public consortium (CIS). The agreements signed were concentrated mainly in the Southern and Southeastern regions and aimed to carry out regional actions, thus contributing to health regionalization. However, challenges related to the process of cooperation and coordination between the health management bodies persist, mainly related to the improvement of linkages between the consortium and the regional health coordination and in-depth social control of these organizations.
\end{abstract}

Key words Health consortium, Federalism, Regionalization, Voluntary transfers
Resumo O objetivo deste artigo é investigar como os consórcios públicos intermunicipais de saúde atuam no Brasil. Para isso, realizou-se uma pesquisa qualitativa do tipo análise documental sobre o conteúdo dos convênios celebrados entre os consórcios com a União, disponíveis no Portal da Transparência da União, no período de 1996 a 2016. Os resultados abordam duas categorias: descrição geral dos convênios celebrados no Brasil e o conteúdo dos convênios celebrados pelos consórcios públicos intermunicipais (CIS). Os convênios celebrados, concentrados principalmente nas regiões Sul e Sudeste, tiveram como objetivo realizar ações de âmbito regional, contribuindo, assim, para o processo de regionalização da saúde. Contudo, desafios relativos ao processo de cooperação e coordenação entre as instâncias gestoras de saúde ainda persistem, sobretudo vinculados à melhoria dos vínculos entre os consórcios com as coordenadorias regionais de saúde e um aprofundamento em relação ao controle social dessas organizações. Palavras-chave Consórcios de saúde, Federalismo, Regionalização, Transferências voluntárias 


\section{Introdução}

O acesso universal aos serviços de saúde, além de ser uma garantia constitucional, é também um desafio compartilhado por todos os entes da federação - União, estados e municípios. Nas últimas décadas, a consolidação do direito à saúde no Brasil aconteceu de forma concomitante ao processo de descentralização das políticas públicas ${ }^{1}$. Inúmeros desafios surgiram com o passar do tempo, principalmentedecorrentes da excessiva fragmentação do desenho federativo formado hoje por 5.570 entes municipais autônomos, sendo que $68 \%$ desses possuem menos de 20 mil habitantes ${ }^{2}$. Além disso, a literatura aponta que a maioria dos municípios vive em uma situação de precariedade técnica, financeira e administrativa que gera, consequentemente, restritas capacidades de atender todas as demandas de saúde da população, principalmente no que tange ao acesso aos serviços de média e alta densidade tecnológica ${ }^{3,4}$.

Tendo em vista essa realidade e as dificuldades de materializar o processo de descentralização de forma plena em muitos municípios, um conjunto de esforços foram feitos pelo Ministério da Saúde, principalmente a partir dos anos 1990, para consolidar o processo de regionalização das políticas de saúde ${ }^{5-9}$. As estratégias governamentais voltaram-se para a consolidação de instâncias regionalizadas de gestão do sistema de saúde, como a organização das Coordenadorias Intergestoras Regionais, a criação das Regiões de Saúde, a consolidação dos consórcios intermunicipais e o estabelecimento da Programação Pactuada Integrada e dos contratos organizativos de ação pública-18.

Mendes et al. ${ }^{8}$ e Medeiros et al. ${ }^{5}$, entendem que o processo de regionalização deve ser compreendido como um modo de organização das ações e dos serviços de saúde em uma região, a fim de assegurar a integralidade da atenção para todos os usuários, possibilitara racionalidade dos gastos efetuados, bem como a otimização dos recursos e a equidade. Santos e Campos ${ }^{7}$ apontam a necessidade de regionalizar a gestão da saúde dentro de um processo complementar ao de descentralização municipal. Nesse caso, o principal argumento proposto pelos autores refere-se à existência de um considerável quantitativo de pequenos municípios que são incapazes de garantir o acesso aosserviços de média e alta densidade tecnológica à população. Desse modo, a regionalização das demandas e dos serviços de saúde seria uma estratégia para garantir o direito à saúde para todos os cidadãos.

Nesse contexto, o surgimento dos consórcios intermunicipais de saúde (CIS) passou a ser con- siderado uma alternativa de organização regional das demandas e dos serviços, a partir de uma proposta de cooperação interfederativa ${ }^{16}$. O estudo de Silva et al. ${ }^{13}$ aponta que os consórcios de saúde, por incluírem diversos municípios dentro de uma mesma região, organizam a demanda por consultas especializadas e por serviços de média e alta complexidade, beneficiando, sobretudo, os municípios de menor porte. Outros trabalhos enfatizam como essas organizações possibilitam a economia na compra de medicamentos ${ }^{19,20}$, de que forma contribuem no acesso aos serviços de média complexidade ${ }^{13,21}$, quais elementos oriundos dos consórcios são facilitadores no processo de desenvolvimento de ações que envolvam cooperação intergovernamental ${ }^{15,22,23}$, qual a satisfação dos usuários dos serviços de saúde ${ }^{24}$ e, por fim, qual a percepção dos gestores que compõem o consórcio sobre os problemas de saúde ambiental $^{16}$.

Abrúcio et al. ${ }^{25}$ afirmam que os consórcios intermunicipais representam um mecanismo de cooperação que extrapola os limites territoriais e administrativos dos municípios. Todavia, a formação dessas organizações é uma escolha autônoma dos municípios, não precisando, necessariamente, obedecer à divisão territorial da Região de Saúde ou da Comissão Intergestora Regional (CIR) da respectiva unidade federativa estadual, nem mesmo coincidir com outra divisão política-institucional do território definida previamente. Dessa forma, a organização autônoma dos consórcios pode contribuir para a fragmentação do sistema de saúde, em que os esforços não se orientam pelo mesmo objetivo, indo na contramão das estratégias de coordenação e cooperação das esferas de gestão de políticas de saúde, ressaltada pela literatura sobre políticas públicas $^{26,27}$. A partir de uma revisão de literatura sobre a produção brasileira sobre o tema, Flexa e Barbastefano ${ }^{28}$ indicam que os consórcios de saúde possibilitam aos municípios ganhos de escala na compra de medicamentos, colaboram com a racionalidade de processos e despesas, além de permitirema realização de projetos regionais conjuntos. Conforme os autores consultados ${ }^{28}$, tais requisitos seriam inviáveis de serem atingidos de forma isolada pelos municípios.

A trajetória das políticas de saúde criou, ao longo do tempo, um conjunto de instâncias gestoras com poder de decisão e alocação de recursos $^{17}$. Com esse grande número de estruturas gestoras e entes federados atuando no desenvolvimento das políticas públicas, autores como Abrúcio e Segatto ${ }^{26}$ e Grin e Abrúcio ${ }^{27}$ ressaltam 
a importância de se pensar estratégias que orientem a cooperação e coordenação federativas entre essas instâncias. Sem construir estratégias de ação nesse sentido, o trabalho realizado de forma isolada por tais estruturas e níveis de governo tenderia a produzir comportamentos predatórios entre as partes, excessos de custos, sobreposição de atividades, vazios assistenciais dentro de um território e, também, competição por recursos. Por isso, articular as esferas de gestão em torno de um pacto pela saúde de âmbito regional tem sido um desafio para as políticas públicas de saúde.

Nesse sentido, esse estudo tem como objetivo investigar como os consórcios públicos intermunicipais de saúde atuam no Brasil a partir das teorias que versam sobre o processo de regionalização da saúde $\mathrm{e}^{10-12,22}$ e cooperação interfederati$\mathrm{va}^{25-27}$. Para tanto, será realizado uma análise de convênios celebrados entre os consórcios de todo o Brasil e a União, no período de 1996-2016. O recorte analítico utilizado justifica-se pelo fato de todos os trabalhossobre consórcios de saúde (CIS) serem "estudos de caso" ${ }^{28}$, carecendo de uma análise mais abrangentesobre o tema. Com isso, esse estudo pretende ampliar o entendimento sobre essas estruturas a partir de um enfoque nacional.

\section{Metodologia}

Este artigo foi desenvolvido em âmbito do doutorado em Sociologia daUniversidade Federal do Rio Grande do Sul (UFRGS). Trata-se de uma pesquisa cujas fontes foram documentais e se encontram disponíveis em arquivos públicos. Foram observados e respeitados os aspectos da integridade em pesquisa, ou seja, essa publicação pressupõe a veracidade e idoneidade dos dados apresentados.

O estudo pode ser caracterizado como uma pesquisa qualitativa com coleta de dados do tipo documental ${ }^{29}$. Essa técnica tem por objetivo compreender as informações contidas nos documentos originais, por intermédio de procedimentos de sistematização e categorização ${ }^{30}$. Para tanto, foram acessados, em setembro de 2017, os convênios celebrados entre a União e os consórcios públicos no Brasil, disponíveis no Portal da Transparência de Recursos Federais da União, no período de 1996 a 2016. Após a coleta das informações organizou-se o material em uma planilha e se examinou o conteúdo das propostas, atentando-se para os objetivos apresentados pe- los consórcios para a celebração dos respectivos convênios.

Ao total, foram celebrados 384 convênios entre a União e os consórcios públicos no período de 1996-2016. Desses, 122 eram voltados à área da saúde, que interessaram à presente pesquisa. A partir da coleta dos documentos que compunham os convênios celebrados, realizou-se análise do conteúdo com base na proposta metodológica de $\operatorname{Bardin}^{30}$, que destaca a materialidade linguística do texto. Esse tipo de análise espera compreender o pensamento dos sujeitos envolvidos no processo que se quer analisar, através do conteúdo expresso no texto, em uma concepção mais transparente de linguagem. Os documentos analisados são peças-chave do processo de transferência de recursos, visto que apresentavam os objetivos e justificativas para a celebração de convênios entre os consórcios e a União.

A partir da análise de conteúdo sobre os consórcios públicos intermunicipais foram elaboradas duas categorias de resultados: 1) descrição geral dos convênios celebrados no Brasil e 2) conteúdo dos convênios celebrados pelos consórcios públicos intermunicipais (CIS). Nessa última parte serão analisadas as propostas apresentadas pelos consórcios à luz do debate sobre regionalização da saúde e coordenação de políticas públicas.

\section{Resultados e discussão}

O Portal da Transparência da União ${ }^{31}$ oferece detalhes dos convênios estabelecidos entre os CIS e a União tais como: objetivo, datas, valores e as cidades que são abrangidas pelo consórcio conveniado. A partir dessa análise, foi possível compreender de forma mais aprofundada que ações são realizadas pelos consórcios de saúde no Brasil.

\section{Descrição geral dos convênios celebrados no Brasil}

Nessa categoria serão analisados dados relacionados com a evolução da celebração de convênio entre União e consórcios intermunicipais no Brasil entre 1996-2016, no geral e em relação à área da saúde especificamente.

A Figura 1 apresenta a distribuição do número de convênios firmados com consórcios intermunicipais de todas as áreas de políticas públicas ao longo do tempo. Verifica-se que o número de convênios estabelecidos entre os consórcios e a União aumentou significativamente, principal- 


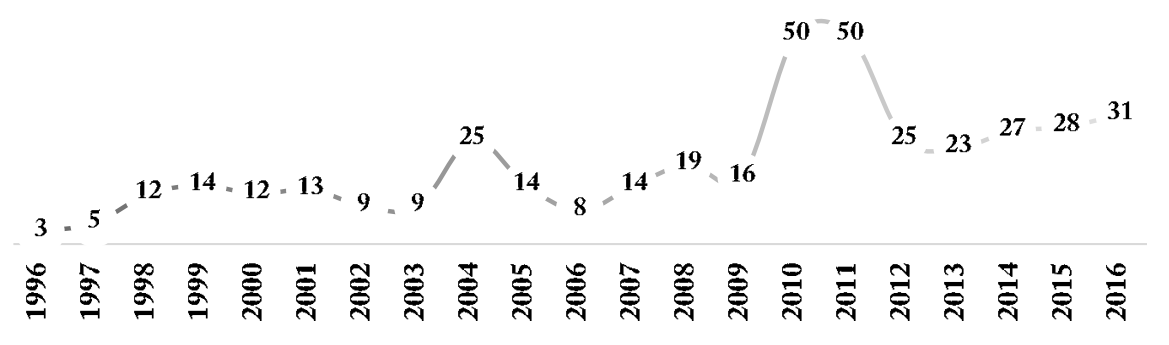

Figura 1. Evolução do número de convênios celebrados entre União e consórcios intermunicipais no Brasil, 1996-2016.

Fonte: Elaborado a partir do Portal da Transparência da União, 2017.

mente nos anos de 2010 e 2011. Todavia, houve uma distribuição irregular ao longo da série histórica.

A Figura 2 apresenta a distribuição percentual dos convênios celebrados entre os consórcios e a União conforme as áreas de políticas públicas. Identifica-se que, dos 384 convênios celebrados no período de 1996 a 2016, a maioria deles, $31,77 \%(\mathrm{n}=122)$ visava promover ações na área da saúde. É possível evidenciar um conjunto bastante diversificado de áreas em que os consórcios estabelecem convênios com a União, embora exista uma concentração desses instrumentos nas áreas da saúde e de desenvolvimento rural.

No tocante à proeminência da área da saúde dentre os convênios firmados, Machado e Andra$\mathrm{de}^{32}$ e Rocha ${ }^{23}$ apontam que a provisão de serviços de saúde passou, ao longo das últimas décadas, a ser competência municipal e, nesse sentido, a sensibilidade do eleitorado para a qualidade da provisão dos serviços prestados é bastante alta. Segundo os autores, este fato faz com que os prefeitos de uma dada região superem os seus conflitos partidários e busquem alternativas para a resolução das demandas. Assim, os consórcios seriam uma ferramenta paragarantir o acesso aos serviços de saúde.

A Figura 3 apresenta o número de convênios voltados à área da saúde por estado da federação. A maioria dos convênios foi firmada por consórcios situados em estados das regiões Sul e Sudeste. A Região Nordeste apresentou apenas um convênio celebrado na área da saúde e a Região
Norte apresentou quatro convênios ao longo dessa série histórica.

Segundo o IBGE2, no ano de 2015, $2.672 \mathrm{mu}-$ nicípios brasileiros (48\% do total) estavam participando de algum consórcio vinculado à área da saúde. Em relação ao número de municípios consorciados por região, identificou-se uma distribuição desigual desses arranjos institucionais no território brasileiro. As regiões Sul e Sudeste contam com, respectivamente, $80 \%$ e $66,48 \%$ de seus municípios consorciados. Nessas regiões, os estados do Paraná e de Minas Gerais destacaram-se por ambos terem 92\% de seus entes consorciados. Quanto às outras regiões, a Centro-Oeste apresentou $37,47 \%$ dos municípios consorciados, a Norte $11,77 \%$ e a Nordeste $27,31 \%{ }^{2}$. Entretanto, o IBGE não contabiliza o número de consórcios existentes e não foram encontradas outras informações oficiais relativas a esse dado. $\mathrm{O}$ estudo de Teixei$\mathrm{ra}^{33}$ constatou, a partir de uma análise baseada no IDHM-Renda, que os municípios consorciados do país possuem uma renda média mais alta do que os não consorciados. Além disso, o estudo mostrou que o consorciamento na área da saúde se difundiu de maneira desigual nas regiões, de acordo com critérios ainda pouco conhecidos. Dentro desse escopo, o presente estudo constatou que é heterogênea a celebração de convênios na área da saúde envolvendo os consórcios e a União, que varia de acordo com o estado e a região do país.

O convênio entre a União e o consórcio é uma transferência voluntária de recursos, o que implica necessariamente a existência de uma negocia- 


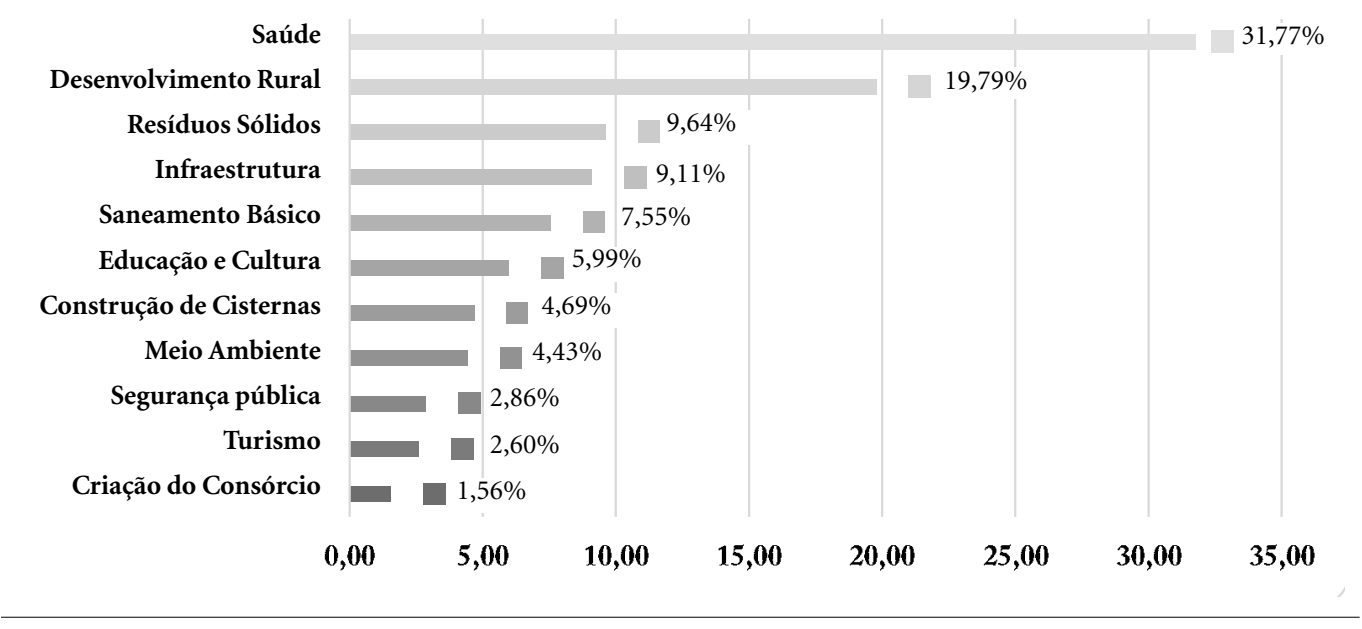

Figura 2. Convênios celebrados pelos consórcios com a União conforme o percentual e a área temática, Brasil, 1996-2016.

Fonte: Elaborado a partir do Portal da Transparência da União, 2017.

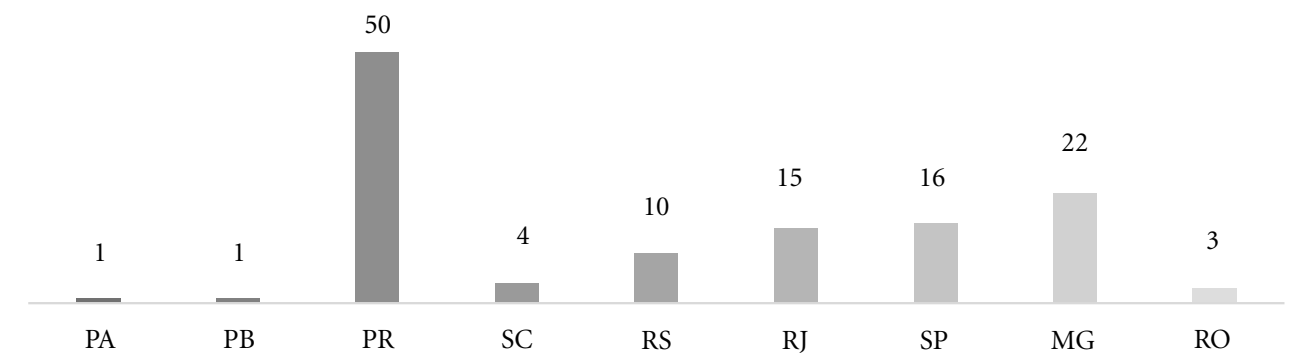

Figura 3. Número de convênios da área da saúde estabelecidos entre consórcios e a União por estado da federação, 1996-2016.

Fonte: Elaborado a partir do Portal da Transparência da União, 2017.

ção política entre esses arranjos institucionais e as esferas de governo central. Conforme evidenciado na Figura 3, os consórcios dos estados da Região Sul e Sudeste ocupam uma posição de destaque na celebração de convênios com a União, enquanto os de outras regiões apresentam, ainda, um tímido desempenho. Em relação à explicação do porquê desse fenômeno, pode-se levantar a hipótese de que esse fato depende da estrutura institucional e da capacidade de articulação dessas organizações com o governo federal. Conforme apontam Abrúcio et al..$^{25}$, a capacidade de construção de uma estrutura institucional que ordene e garanta o desenvolvimento das ações é fundamental para a manutenção das atividades dos consórcios. O estudo de Meireles $^{34}$, relativo à lógica das transferências voluntárias da União aos municípios, dá suporte a essa tese na medida em que o autor aponta que elementos como pressão política, partidos políticos e barganha são determinantes no processo de obtenção de recursos voluntários da União, categoria onde se enquadram os convênios com os consórcios. 
Destaca-se que os consórcios do estado do Paraná conseguiram firmar 41\% $(\mathrm{n}=50)$ de todos os convênios celebrados na área da saúde no período analisado. Os estudos de $\operatorname{Rocha}^{23} \mathrm{e}$ Ferraes e Cordoni Júnior ${ }^{20}$ pontuam que alguns consórcios paranaenses têm por objetivo realizar a compra de medicamentos, enquanto outros se dedicam à gestão do Serviço de Assistência Médica de Urgência (SAMU). Além disso, os estudos indicam que a maioria desses consórcios tem por objetivo organizar as demandas por serviços de média e alta complexidade nas regiões que atuam. Os autores afirmam que há casos em que um município participa de mais de um consórcio e que há consórcios englobando municípios de outros estados da federação, como de Santa Catarina. Ou seja, a lógica de formação desses arranjos institucionais é permeada por conflitos e parcerias formalizadas pelos prefeitos que compõem essas estruturas, as quais podem, inclusive, extrapolar o território estadual. Nesse sentido, identifica-se que o processo de constituição e funcionamento dos consórcios não segue, necessariamente, o desenho institucional das Regiões de Saúde previsto pela Secretaria Estadual de Saúde do Paraná. Por fim, ressalta que, a despeito dessas questões, os consórcios paranaenses foram hábeis e bem sucedidos no processo de obtenção de recursos por parte do governo federal.

Observa-se na Figura 4 a distribuição temporal da celebração de convênios voltados à área da saúde, entre consórcios e União. Verifica-se que houve um aumento na celebração de convênios, embora de forma não linear e com grande variação no período 1996-2016. Conforme Linhares et al. ${ }^{35}$ a Lei dos Consórcios, promulgada em 2005, produziu um aumento significativo no número de municípios consorciados no Brasil. Todavia, identifica-se que os consórcios tiveram um desempenho heterogêneo na busca de financiamento para suas ações, materializado na celebração de convênios com a União ao longo da série histórica.

\section{O conteúdo dos convênios celebrados pelos consórcios públicos intermunicipais com a União}

Nesta seção analisam-se os objetivos dos convênios relacionados à área da saúde. Para tanto, foram classificados os tipos de ações que os consórcios pretendiam executar, conforme apresentados na Figura 5.

Verifica-se que 66\% dos convênios celebrados $(\mathrm{n}=81)$ nessa área tiveram como objetivos a aquisição de equipamentos hospitalares, a melhoria da estrutura física dos serviços de saúde e a compra de materiais permanentes. Além disso, destaca-se o fato de que $7 \%(n=9)$ dos convênios celebrados visavam a construção de estruturas físicas onde funcionariam serviços de saúde e outros 7\% buscavam adquirir unidades móveis para os municípios consorciados.

Observa-se que alguns consórcios organizam estruturas próprias de implementação de políticas públicas, ou seja, eles constroem e mantêm serviços de saúde cujo objetivo é fornecer o atendimento direto à população. Por outro lado, identifica-se que outros consórcios atuam de modo a auxiliar os municípios na manutenção dos serviços se saúde (por exemplo, compra de materiais permanentes para os hospitais), tornando-se assim uma estrutura de apoio técnico, operacional e administrativo, sem ter a pretensão de prestar serviços de atendimento direto à população.

Os objetivos dos convênios apresentados pelos consórcios à União revelam um conjunto defragilidades dos municípios das regiões em que estão inseridos, para os quais os recursos seriam destinados. A partir da análise dos documentos que compõem os convênios celebrados se identificaram referências ao conceito de regionalização da saúde. De modo ilustrativo, cita-se o convênio celebrado no ano de 2010 por um consórcio situado no sul do estado do Paraná que conta com 20 municípios consorciados. Os documentos relativos demonstram que o consórcio buscava a construção de um prédio onde funcionaria um centro regional de especialidades médicas e a justificativa para a captação de recursos, descrita no objetivo do convênio, foi precisamente a diminuição das filas dos serviços de saúde localizados na capital, Curitiba, e a criação de um centro regional de referência a fim de regionalizar o atendimento dos serviços de média complexidade.

Por outro lado, verificou-se que alguns convênios apresentavam, na descrição do objetivo, uma arguição a respeito da importância do investimento para a região. Cita-se aqui o trecho de um convênio estabelecido por um consórcio mineiro no ano de 2012, com a seguinte justificativa:

O objetivo da execução do objeto do convênio visa a compra de equipamentos para criar condições de implantar serviços de saúde para atender a região dos municípios consorciados, cujo benefício é criar condições à população local de ser atendida na própria região, evitando o seu deslocamento para os grandes centros saturados ${ }^{31}$. 


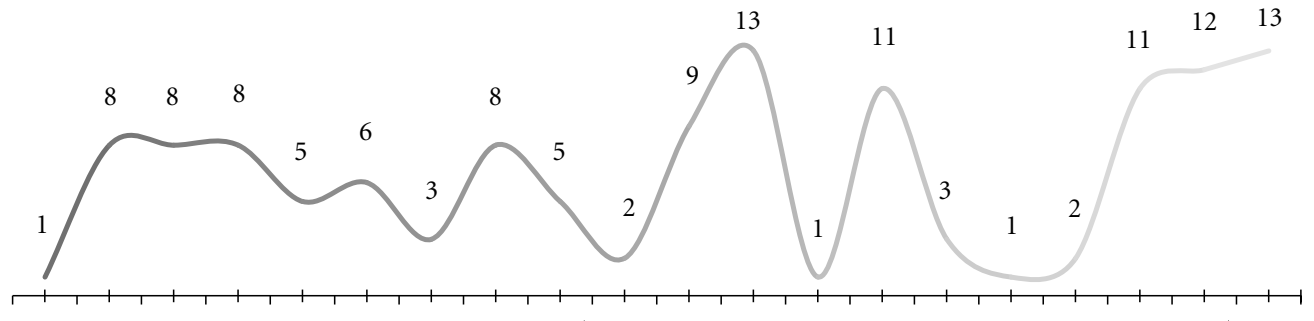

19961998199920002001200220032004200520062007200820092010201120122013201420152016

Figura 4. Evolução do número de convênios estabelecidos entre consórcios na área da saúde e a União, por ano, Brasil, 1996-2016.

Fonte: Elaborado a partir do Portal da Transparência da União, 2017.



Figura 5. Objetivo dos convênios estabelecidos entre consórcios de saúde e a União, por tipo, Brasil, 1996-2016.

Fonte: Elaborado a partir do Portal da Transparência da União, 2017. 
Nesse sentido, o documento demonstra uma sensibilidade do consórcio para questões cruciais relacionadas com a gestão da oferta para o atendimento da demanda no Sistema Único de Saúde.

Em outro caso, aponta-se um convênio celebrado por um consórcio situado em Rondônia, em 2011 que pretendia captar recursos federais para a aquisição de determinados aparelhos hospitalares (aparelho de radiografia e de mamografia) ${ }^{31}$. Além disso, consta nos objetivos do convênio que quem administraria tais equipamentos seria o município de referência da região e não o próprio consórcio. Assim, o consórcio estaria associado aos interesses dos municípios daquele território e seria um facilitador para o acesso aos recursos federais, mas não o prestador do serviço. Em outros casos, os objetivos dos convênios identificados referiam-se à compra de veículos como ambulâncias e UTI móveis, a fim de equipar os serviços de saúde já existentes nos municípios de referência ${ }^{31}$. Todavia, percebe-se que a concepção de serviço de saúde da maioria dos consórcios está vinculada à um modelo centrado na medicina curativa e hospitalocêntrica ${ }^{36}$, baseada na produção de atendimento de média e alta complexidade. Contrariando essa tendência, observa-se que uma minoria dos convênios ( 6 ao todo) apresentava como proposta a construção de academias de terceira idade, com o objetivo de melhorar a qualidade de vida dos idosos.

Identifica-se que os gestores dos consórcios estão cientes dos efeitos negativos que o processo de descentralização do atendimento à saúde provocou nos municípios brasileiros. Por conta disso, essas organizações propõem ações de regionalização do atendimento à saúdena medida em queapresentam propostas para construir estruturas regionais de provisão de serviços de saúde e para garantir oauxílio financeiro aos municípios de referência das regiões. Contudo, desafios ainda persistem. Vale destacar que não fica claro se e como tais iniciativas convergem com o trabalho das Comissões Intergestoras Regionais e as diretrizes da Programação Pactuada Integrada situadas dentro de cada estado da federação. Além disso, os consórcios de saúde não contam com instrumentos de participação, dificultando o controle social sobre suas atividades ${ }^{28}$.

O estudo de Botti et al. ${ }^{22}$ chama a atenção para o fato dos consórcios se preocuparem mais com a oferta direta de serviços do que com a construção de um sistema de saúde que busque a integralidade e coordenação assistencial. Nesse contexto, os autores afirmam que os consórcios conseguem ampliar o acesso aos serviços especializados nas regiões que atuam, contudo, persistem desafios relativos à construção de um sistema de referência e contra referência entre os serviços de saúde. O estudo de Nicoletto et al. ${ }^{21}$, realizado em um estado do Sul do Brasil, aponta que a oferta de consultas especializadas pelos consórcios não é suficiente para atender a demanda, bem como existem inúmeras falhas nos seus mecanismos de referência e contra referência. Nessa mesma linha, os autores enfatizam que os consórcios possuem potencial para ampliar a oferta de serviços, todavia, essas ações precisam ser planejadas e adequadas ao sistema de referência estipulado pelo Sistema Único de Saúde.

Portanto, a partir dessa análise, volta-se à problemática lançada por Grin e Abrúcio ${ }^{27}$ e Segatto e Abrúcio $^{26}$ relativa à construção de um sistema coordenado e cooperativo de produção de políticas públicas no Brasil. Os estudos internacionais sobre o tema ${ }^{37-43}$, desenvolvidos em países como Espanha, Alemanha e Canadá, também destacam a importância de serem construídos sistemas de cooperação e coordenação intergovernamental que busquem conciliar as demandas locais com as políticas desenvolvidas pelos governos centrais a fim de garantir o acesso universal à saúde.

Cabe ainda ressaltar algumas limitações desse estudo como o fato da pesquisa estar baseada nos convênios celebrados pelos consórcios intermunicipais com a União, sem considerar os acordos firmados pelos governos estaduais. A análise limitou-se aos objetivos contidos nos documentos oficiais apresentados para o estabelecimento do convênio, não considerando a efetiva implementação dos recursos pleiteados, o que demandaria uma pesquisa in loco.

\section{Conclusão}

Este estudo buscou realizar uma descrição geral dos convênios celebrados na área da saúde entre os consórcios públicos intermunicipais e a União, demonstrando que a evolução temporal da celebração desses convênios variou muito ao longo do tempo e que os municípios das regiões Sul e Sudeste apresentaram um número maior de convênios em comparação com as outras regiões.

Quanto ao conteúdo dos convênios, constatou-se que os consórcios estão cientes das problemáticas que envolvem a descentralização das políticas de saúde e se apropriam do conceito de regionalização da saúde para fazerem a requisição de recursos junto ao Ministério da Saúde. 
Todavia, a análise dos dados sugere que os consórcios ainda atuam de forma autônoma e desconectada de outras instâncias de gestão, tais como as Coordenadorias Regionais de Saúde, o que pode provocar descompassos e sobreposições de atividades. Além disso, destaca-se que os consórcios carecem de mecanismos que estimulem a participação e o controle social, aspectos

\section{Colaboradores}

L Lui e LM Schabbach participaram da coleta e análise dos dados. CR Dalla Nora contribuiu com a revisão e análise dos dados. As pesquisas compõem a pesquisa de doutorado de L Lui sobre a atuação dos consórcios intermunicipais de saúde. inerentes e fundamentais para a consolidação do SUS ${ }^{44,45}$. Por fim, ressalta-se a necessidade de se realizar mais estudos sobre o tema, principalmente enfatizando a forma como os consórcios públicos se relacionam com outras instâncias de gestão e controle social na área de saúde, bem como com outras esferas de governo.

\section{Referências}

1. Arretche M. Federalismo e igualdade territorial: uma contradição em termos? Dados 2010; 53(3):587-620.

2. Instituto Brasileiro de Geografia e Estatística (IBGE). Perfil dos Municípios Brasileiros. Rio de Janeiro: IBGE; 2015.

3. Grin EJ, Nascimento AB, Abrucio FL, Fernandes AS. Sobre desconexões e hiatos: uma análise de capacidades estatais e finanças públicas em municípios brasileiros. Cad Gestão Pública Cidadania 2018; 23(76):312-336.

4. Arretche M. Democracia, Federalismo e Centralização no Brasil. Rio de Janeiro: Editora Fiocruz, FGV; 2012.

5. Medeiros CRG, Saldanha OMFL, Grave MTQ, Koetz LCE, Dhein G, Castro LC, Schwingel G, Santos MV. Planejamento regional integrado: a governança em região de pequenos municípios. Saúde Soc 2017; 26(1):129-140.

6. Carvalho ALB, Jesus WLA, Senra IMVB. Regionalização no SUS: processo de implementação, desafios e perspectivas na visão crítica de gestores do sistema. Cien Saude Colet 2017; 22(4):1155-1164.

7. Santos L, Campos GWS. SUS Brasil: a região de saúde como caminho. Saúde Soc 2015; 24(2):438-446.

8. Mendes Á, Louvison MCP, Ianni AMZ, Leite MG, Feuerwerker LCM, Tanaka OY, Duarte L, Weiller JAB, Lara NCC, Botelho LAM, Almeida CAL. O processo de construção da gestão regional da saúde no estado de São Paulo: subsídios para a análise. Saúde Soc 2015; 24(2):423-437.

9. Garnelo L, Sousa ABL, Silva CO. Regionalização em Saúde no Amazonas: avanços e desafios. Cien Saude Colet 2017; 22(4):1225-1234.

10. Moreira MR, Ribeiro JM, Ouverney AM. Obstáculos políticos à regionalização do SUS: percepções dos secretários municipais de Saúde com assento nas Comissões Intergestores Bipartites. Cien Saude Colet 2017; 22(4):1097-1108.

11. Albuquerque MV, Lima LD, Oliveira RAD, Scatena JHG, Martinelli NL, Pereira AMM. Governança regional do sistema de saúde no Brasil: configurações de atores e papel das Comissões Intergovernamentais. Cien Saude Colet 2018; 23(10):3151-3161.

12. Duarte LS, Pessoto UC, Guimarães RB, Heimann LS, Carvalheiro JR, Cortizo CT, Ribeiro EAW. Regionalização da saúde no Brasil: uma perspectiva de análise Saúde Soc 2015; 24(2):472-485. 
13. Silva CR, Carvalho BG, Cordoni Júnior L, Nunes EFPA. Dificuldade de acesso a serviços de média complexidade em municípios de pequeno porte: um estudo de caso. Cien Saude Colet 2017; 22(4):1109-1120.

14. Santos AM, Giovanella L. Gestão do cuidado integral: estudo de caso em região de saúde da Bahia, Brasil. Cad Saúde Pública 2016; 32(3):e00172214.

15. Galindo JM, Cordeiro JC, Villani RAG, Barbosa Filho EA, Rodrigues CS. Gestão interfederativa do SUS: a experiência gerencial do Consórcio Intermunicipal do Sertão do Araripe de Pernambuco. Rev Administração Pública 2014; 48(6):1545-1566.

16. Morais VS, Chaves APL. Percepção dos gestores municipais de saúde relacionada à saúde ambiental: consórcio intermunicipal de saúde Cerrado Tocantins Araguaia. Saúde Soc 2016; 25:349-360.

17. Vieira FS. Avanços e desafios do planejamento no Sistema Único de Saúde. Cien Saude Colet 2009; 14(Supl. 1):1565-1577.

18. Menicucci TMG, Marques AMF, Silveira GA. O desempenho dos municípios no Pacto pela Saúde no âmbito das relações federativas do Sistema Único de Saúde. Saúde Soc 2017; 26(2):348-366.

19. Amaral SMS, Blatt CR. Consórcio intermunicipal para a aquisição de medicamentos: impacto no desabastecimento e no custo. Rev Saúde Pública 2011; 45(4):799-801.

20. Ferraes AMB, Cordoni Junior L. Consórcio de medicamentos no Paraná: análise de cobertura e custos. Rev Administração Pública 2007; 41(3):475-486.

21. Nicoletto SCS, Cordoni Jr. L, Costa NR. Consórcios Intermunicipais de Saúde: o caso do Paraná, Brasil. Cad Saúde Pública 2005; 21(1):29-38.

22. Botti CS, Artmann E, Spinelli MAS, Scatena JHG. Regionalização dos Serviços de Saúde em Mato Grosso: um estudo de caso da implantação do Consórcio Intermunicipal de Saúde da Região do Teles Pires, no período de 2000 a 2008. Epidemiol Serviços Saúde 2013; 22(3):491-500.

23. Rocha CV. A cooperação federativa e a política de saúde: o caso dos Consórcios Intermunicipais de Saúde no estado do Paraná. Cad Metrópole 2016; 18(36):377-399.

24. Muller EV, Greco M. Avaliação da satisfação dos usuários com os serviços do consórcio intermunicipal de saúde do noroeste do Paraná. Cien Saude Colet 2010; 15(3):925-930.

25. Abrucio FL, Filippim ES, Dieguez RC. Inovação na cooperação intermunicipal no Brasil: a experiência da Federação Catarinense de Municípios (Fecam) na construção de consórcios públicos. Rev Administração Pública 2013; 47(6):1543-1568.

26. Segatto CI, Abrucio FL. A cooperação em uma federação heterogênea: o regime de colaboração na educação em seis estados brasileiros. Rev Bras Educação 2016; 21(65):411-429.

27. Grin EJ, Abrucio FL. Quando "feds" e "locals" não falam a mesma língua: uma análise sobre dissonâncias na cooperação federativa. Cad EBAPEBR 2017; 15(3):694-719.

28. Flexa RGC, Barbastefano RG. Consórcios Públicos de Saúde: Uma revisão da literatura. Cien Saude Colet 2020; 25(1):325-338.

29. Marconi MA, Lakatos EM. Técnicas de Pesquisa. São Paulo: Atlas; 1991.
30. Bardin L. Análise de conteúdo. Lisboa: Edições 70; 2011.

31. Brasil. Portal da Transparência da União [Internet]. 2018 [acessado 2018 Set 11]. Disponível em: http:// www.portaltransparencia.gov.br/

32. Machado JA, Andrade MLC. Cooperação intergovernamental, consórcios públicos e sistemas de distribuição de custos e benefícios. Rev Administração Pública 2014; 48(3):695-720.

33. Teixeira LS. Ensaios sobre consórcios intermunicipais de saúde: financiamento, comportamento estratégico, incentivos e economia política. Brasília: Câmara dos Deputados, Coordenação de Publicações; 2007.

34. Meireles F. Alinhamento partidário e demanda por transferências federais no Brasil. Rev Administração Pública 2019; 53(1):173-194.

35. Linhares PTFS, Messenberg RP, Ferreira APL. Transformações na federação brasileira: o consórcio intermunicipal no Brasil do início do século XXI [Internet]. IPEA; 2017 [acessado 2018 Set 12]. Disponível em: http://repositorio.ipea.gov.br/handle/11058/8102

36. Viana AL d'Ávila, Bousquat A, Melo GA, Negri Filho AD, Medina MG. Regionalização e Redes de Saúde. Cien Saude Colet 2018; 23(6):1791-1798.

37. Wallner J. Cooperation without the Leviathan: Intergovernmental policymaking in Canadian education. Regional Federal Studies 2017; 27(4):417-440.

38. Simmons JM. Canadian multilateral intergovernmental institutions and the limits of institutional innovation. Regional Federal Studies 2017; 27(5):573-596.

39. Dasí JF, Fons AG. La contribución de las fórmulas existentes de cooperación intermunicipal en la equidad territorial: el caso de la Mancomunitat de la Ribera Alta. Estudios Geográficos 2018; 78(283):465-491.

40. González JR. El gobierno del territorio en España: balance de iniciativas de coordinación y cooperación territorial. Boletín de la A.G.E. 2005; 39:59-86.

41. Montpetit É, Foucault M. Canadian Federalism and Change in Policy Attention: A Comparison with the United Kingdom. Canadian J Political Sci 2012; 45(3):635-656.

42. Auel K. Intergovernmental relations in German federalism: Cooperative federalism, party politics and territorial conflicts. Comparative Eur Politics 2014; 12(4):422-443.

43. Kwon S-W, Feiock RC. Overcoming the Barriers to Cooperation: Intergovernmental Service Agreements. Public Administration Rev 2010; 70(6):876-884.

44. Leal AF, Lui L. Instituições participativas e seus efeitos nas políticas públicas: estudo do Comitê de Mortalidade por Aids de Porto Alegre. Saúde Soc 2018; 27(1):94-105.

45. Côrtes SV. Sistema Único de Saúde: espaços decisórios e a arena política de saúde. Cad Saúde Pública 2009; 25(7):1626-1633.

Artigo apresentado em 20/11/2018

Aprovado em 15/04/2019

Versão final apresentada em 17/04/2019 